\section{COMPLEMENTARY USE OF APFIM AND TEM FOR A STUDY OF PRECIPITATION IN A RAPIDLY SOLIDIFIED STAINLESS STEEL}

\author{
T. F. Kelly", S. Wisutmethangoon ", D. J. Larson ${ }^{* *}$, and M. K. Miller ${ }^{* *}$
}

"Department of Materials Science and Engineering, University of Wisconsin, Madison, WI 53706, ** Metals and Ceramics Division, Oak Ridge National Laboratory, Oak Ridge, TN 37831-6376.

Stainless steels are important technologically for a wide range of applications. Though these steels are attractive for their environmental stability, austenitic versions of stainless steels are not generally known for their high strength. Many rapid-solidified stainless steels have been processed by gas atomization. Recently, strength improvements of over $50 \%$ relative to conventionallyprocessed stainless steels have been achieved with concomitant improvement in corrosion and oxidation behavior. ${ }^{1}$ These strength improvements are most pronounced when elevated concentrations of oxygen and vanadium are present in the metal. However, the precise role of these elements and their location in the microstructure has not been determined.

The specimen material (Fe-16 wt $\%$ Ni-9\% $\mathrm{Cr}-0.5 \%$ Mn- $0.2 \% \quad \mathrm{~V}-0.0137 \% \quad \mathrm{~N}-0.008 \% \quad \mathrm{O}$ ) was prepared by gas atomization and hot extrusion followed by precipitation aging as described elsewhere. ${ }^{2}$ Transmission electron microscopy (TEM) observation of these austenitic steels revealed $20 \mathrm{~nm}$ precipitates on dislocations, Fig. 1a. No smaller precipitates were observed in the grain interiors with diffraction contrast bright-field imaging. However, Moire fringe contrast was observed throughout the material with weak-beam dark-field imaging, Fig. 1b. It is not difficult to establish if this Moire fringe contrast is due to small coherent precipitates or to a surface oxide coating.

Field ion microscopy (FIM) of this steel revealed ultrafine ( 5 to $10 \mathrm{~nm}$ diameter) brightly-imaging precipitates, Fig. 2. Atom probe analysis revealed that these nitride precipitates were enriched in chromium and vanadium ${ }^{2}$. These precipitates were observed both in the interior of the grain and also at internal interfaces. For example, the precipitates shown in Fig. 2 are decorating an interface.

It is generally possible to ascertain the type of interface by determining the orientation relationship between the regions either side of the interface from the field ion image. This determination requires that there is a sufficient large area that exhibits a number of ring systems in the field ion image (i.e., the crystallographic poles) to enable the orientation of each region to be established. Unfortunately, few poles are generally evident in the field ion images of austenitic stainless steels.

Since the apex region of the field ion specimen is electron transparent, TEM may be used to determine the nature of this interface. A dark-field TEM image of the FIM specimen taken under 2beam conditions with $\vec{g}=331$ is shown in Fig. $3 \mathrm{a}$. Three grains are evident in this image where the middle grain is imaging darkly. The bright grain at the tip of the specimen corresponds to the region which is imaged in the lower section of Fig. 2. Electron diffraction patterns were recorded from the two larger grains and a standard FCC twin orientation relationship was found suggesting that the dark grain in Fig. $3 \mathrm{a}$ is a twin and that the interface shown in Fig. 2 is therefore a twin boundary. It appears from the contrast and the shape and orientation of the interfaces that the interface near the apex must also be a twin interface. A higher magnification image of the apex region is shown in Fig. 3b. It is apparent in this image that it is difficult to observe precipitates at twin interfaces at strong diffracting conditions in TEM.

It is clear that the nanometer-scale precipitates that form during aging of a rapidly solidified stainless steel image clearly in the FIM but are difficult to distinguish in the TEM. The composition of these precipitates can be reliably determined in the atom probe. However, reliable identification of a twin interface in these materials requires TEM characterization of the FIM specimen. This study illustrates how APFIM and TEM complement each other in nano-scale characterization of materials. ${ }^{3}$

\title{
References
}

1. J. E. Flinn and T. F. Kelly, US patent application submitted April 1996.

2. S. Wisutmethangoon, T. F. Kelly, P. P. Camus, J. E. Flinn, D. J. Larson, and M. K. Miller, submitted to these proceedings.

ISTRIBUTION OF THIS DOCUMENT IS UNLIMTED
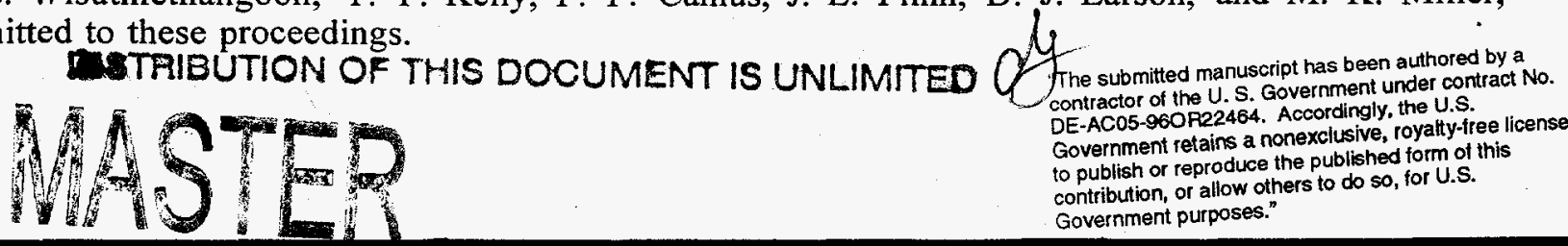


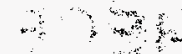

3. This research was sponsored by the Division of Materials Sciences, U. S. Department of Energy, under contract DEAC05-960R22464 with Lockheed Martin Energy Research Corp. and was conducted utilizing the Shared Research Equipment User Program facilities at Oak Ridge National Laboratory.
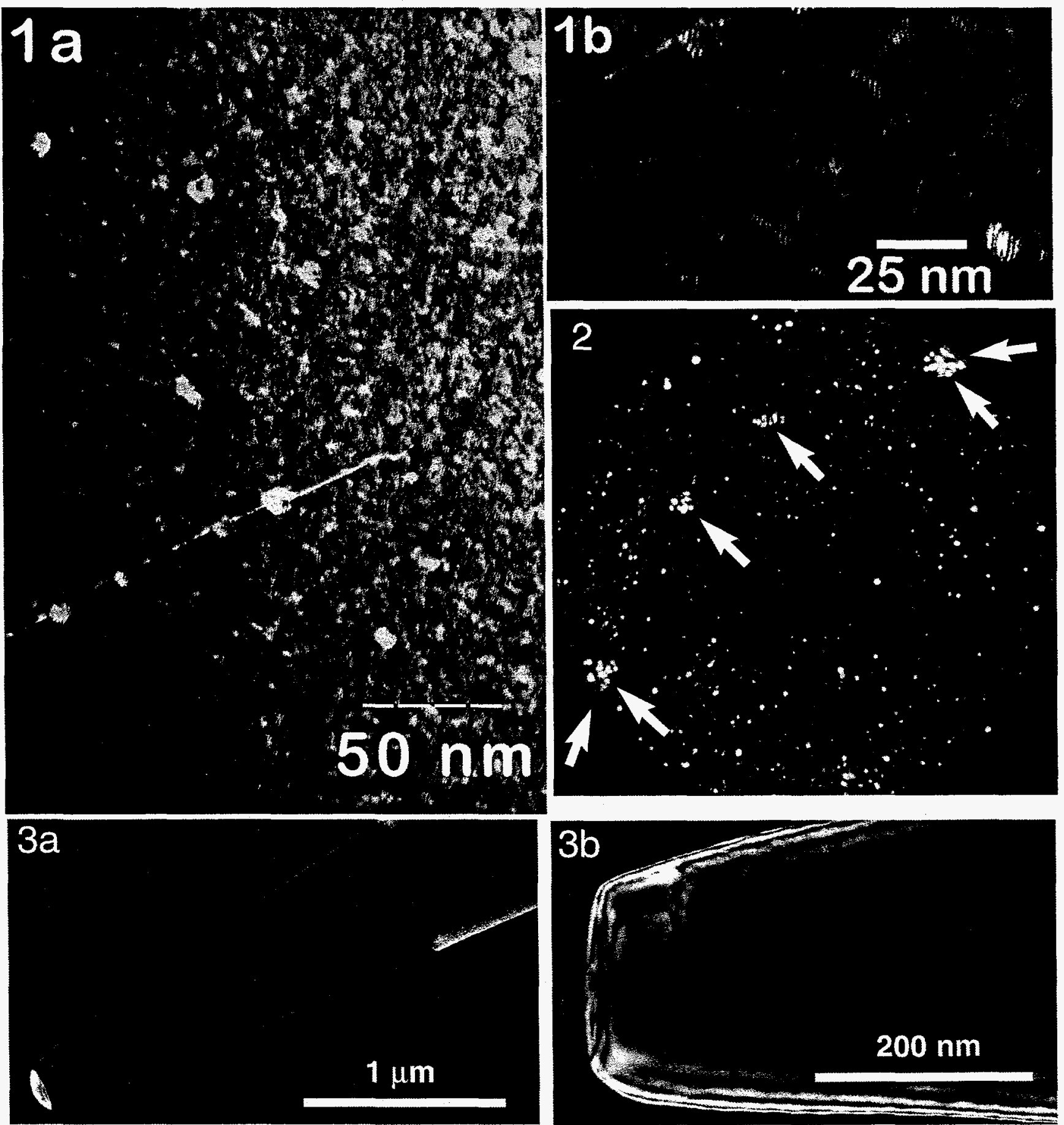

FIG. 1 a) Weak-beam image of $\mathrm{Fe}-16 \mathrm{Ni}-9 \mathrm{Cr}$ alloy. b) Enlargement of a) showing Moire fringe contrast throughout the structure.

FIG. 2 Field ion image of 5 to $10 \mathrm{~nm}$ diameter nitride precipitates located on an interface.

FIG. 3 a) Dark field TEM image of the FIM specimen in FIG. 2. b) Dark field TEM image of the apex of the specimen in FIG. 2. 


\section{DISCLAMIER}

Portions of this document may be illegible in electronic image products. Images are produced from the best available original document. 



\section{DISCLAIMER}

This report was prepared as an account of work sponsored by an agency of the United States Government. Neither the United States Government nor any agency thereof, nor any of their employees, makes any warranty, express or implied, or assumes any legal liability or responsibility for the accuracy, completeness, or usefulness of any information, apparatus, product, or process disclosed, or represents that its use would not infringe privately owned rights. Reference herein to any specific commercial product, process, or service by trade name, trademark, manufacturer, or otherwise does not necessarily constitute or imply its endorsement, recommendation, or favoring by the United States Government or any agency thereof. The views and opinions of authors expressed herein do not necessarily state or reflect those of the United States Government or any agency thereof. 
